\title{
CALIBRATION OF SENSORS FOR MEASURING LOAD IN SHREDDING MACHINES
}

\author{
Ing. Juraj BENIAK, PhD. \\ Strojnícka fakulta STU v Bratislave, Nám.slobody 17, 81231 Bratislava, \\ email: juraj.beniak@stuba.sk
}

\begin{abstract}
Research and development of new types of machines, their innovation and improvement is inherently linked to understanding the construction of machine nodes and individuel machine parts. Based on knowledge and experience we can optimize the design of equipment and minimize its power consumption for optimal performance. A specialty of shredding machines is a high diversity in the process of disintegration and processed raw materials. Technology of disintegration is stochastic with respect to the principle of disintegration with regard to the processed type of raw material. Design of new machines is mainly based on gained experiences, which considerably increases the time needed for designing and manufacturing new types of devices. To describe this process, it must be supported by a number of measurements on devices that are suitable for the process. Considering these facts, an experimental measurement stand was designed, to measure the influence of basic parameters affecting the process of disintegration. The stand was designed to allow both direct and indirect measurement of the analyzed variables. It is possible to directly measure the value of disintegration force, on the shredding wedge, required for the disintegration of the material. Before measuring, it is necessary to calibrate the measuring system, in order to obtain relevant values.
\end{abstract}

KEY WORDS: shredding machine, shredding force

\section{INTRODUCTION}

In this article we will deal with sensor calibration, which are placed on the disintegration wedges. Calibration must be done because, after preparation and application of sensors on the wedges surface, we do not know what the relationship between the voltage readings received from the electrodes of the piezoelectric sensors and torque required for the disintegration that we wish to find out. For this reason, we have to assign a measured voltage value with a known torque. Calibration of gauge means a set of actions that give, for certain conditions, a relationship between values indicated by the gauge and the corresponding values of variables realized by reference or working etalon [1] [2] [3] [4]. Calibration involves the process of establishing a calibrated gauge to etalon, and transfer values of etalon to the calibrated gauge respectively. With few exceptions, this takes a way of direct or indirect comparisons [3].

The purpose of calibration is to determine from the calibration experiment, estimates of unknown parameters and their uncertainties and covariance's. Because of this the calibration experiment is carried out and the model for calibration evaluation will be prepared [3]. From a mathematical point of view the aim of gauge calibration is to determine the correlation between $X$ data of calibrated gauge with value of etalon $t$, including the determination of uncertainties of this dependence. Dependence of the value of calibrated gauge from an etalon $X=f(t)$ is called the transformation function of the sensor. Inverse function of the transformation function, is the dependence $t=g(X)$ is called sensor calibration function [4]. 
Calibration is performed by comparing calibrated gauge values with etalon values, an exposure to the same parameter. Differentiation of values of acting parameter for calibration scale, by which the calibrated gauge comparing with etalon, we normally choose uniformly, a number $n \geq 6$. Assuming that the values of the variable applied to the calibrated gauge and to the etalon are the same (this doesn't always have to apply), we will fold over the measured values $X_{j}$ the regression polynomial dependence on the type of degree $p$. We consider a polynomial of degree $p$ for the transformation function in the form [2]

$$
X=a_{0}+a_{1} t+a_{2} t^{2}+\ldots . .+a_{p} t^{p}
$$

And calibration function in the form

$$
t=b_{0}+b_{1} X+b_{2} X^{2}+\ldots . .+b_{p} X^{p}
$$

If calibration is carried out with $n$ values from $t_{1}$ to $t_{n}$ and taking into account the possible effects in the transmission of values from etalon to calibrated gauge, we get a theoretical model of calibration in the form

$$
\begin{aligned}
& X_{1}=a_{0}+a_{1} t_{1}+a_{2} t_{1}^{2}+\ldots . .+a_{\mathrm{p}} t_{1}^{p} \\
& X_{2}=a_{0}+a_{1} t_{2}+a_{2} t_{2}{ }^{2}+\ldots . .+a_{\mathrm{p}} t_{2}^{p}
\end{aligned}
$$

$$
X_{n}=a_{0}+a_{1} t_{n}+a_{2} t_{n}^{2}+\ldots . .+a_{\mathrm{p}} t_{n}^{p}
$$

where

$X j$ is the value of calibrated gauge (reproduced, measured) for the value of parameter $j$ applied on calibrated gauge,

$t_{j}$ is the $j$ value of etalon (reproduced, measured),

$a_{0}, a_{1}, \ldots, a_{p}$ - unknown parameters output value, which are investigated by calibration, $n \geq p+1$.

\section{SENSORS CALIBRATION ON WEDGES OF MEASUREMENT STAND OF DESINTEGRATIVE DEVICE}

On the measurement apparatus we can read the value of voltage. To this value we have to assign a value of torque, which corresponds to the wedge deformation where the sensor is located. For this purpose we need to apply a known torque.

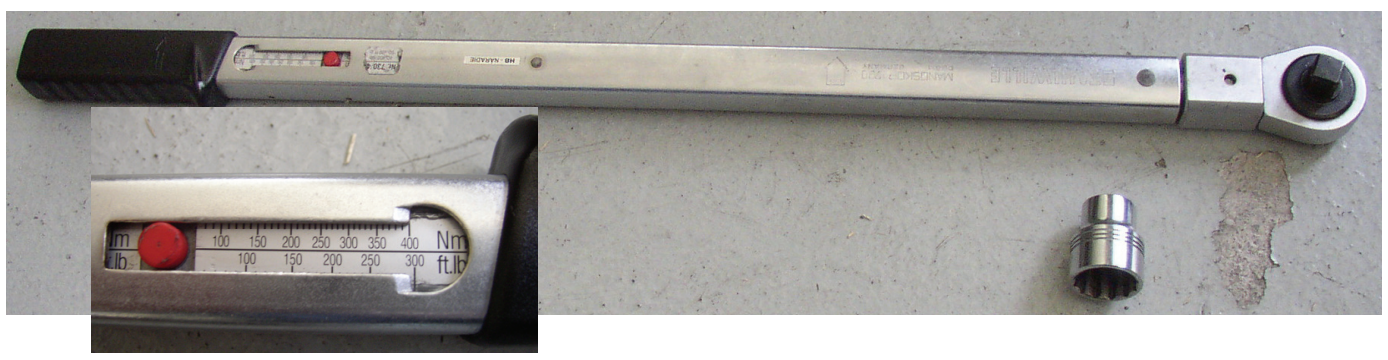

Fig. 1 Torque wrench used for calibration 
As an etalon we chose the torque wrench, with which we can apply the torque on the drive shaft. The torque wrench used (Fig. 1) has a range of adjustable torque values from 80 to $400 \mathrm{Nm}$ (Fig. 1) with graduations of $10 \mathrm{Nm}$. This range was sufficient because maximum calculated torque is $425 \mathrm{Nm}$. The range of torque wrench approximately covers the working range for the torque of the measurement stand. The inaccuracy of the torque wrench was detected in a specialized laboratory before the calibration started. The manufacturer of the torque wrench declares an error of $4 \%$ [5]. When calibrating the torque wrench, which took place directly before the measurement, we found the maximum error of the instrument $\Delta=6 \mathrm{Nm}$.

To be able to transfer torque from a torque wrench on the shaft with tool holders, we had to make a tool - extension (Fig. 2) as a reducing part between the shaft and the torque wrench ending. On the figure 2 we can see the connection of torque wrench through an adapter to the shaft of the measuring stand.

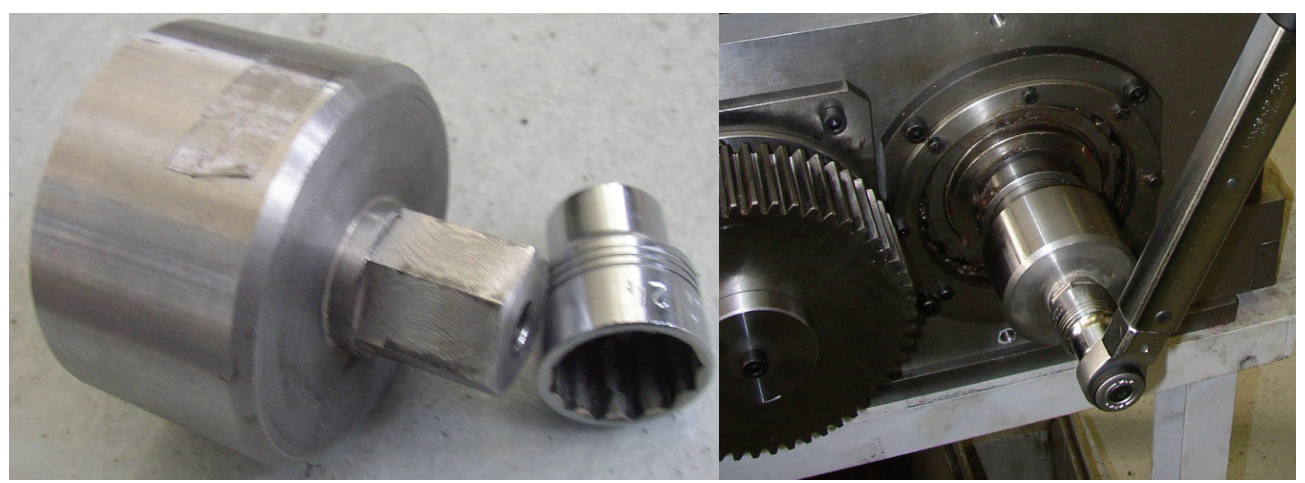

Fig. 2 Correcting part for joining of torque wrench to spindle of measurement stand of disintegrative device

Calibration process proceeds as follows: On torque wrench we set the torque value at which we will measure the voltage on the sensors. On the disintegrative disk we will mount the disintegrative wedge of which sensors will be calibrated. Then we will block this wedge in the area where the two disks are meeting on the top of the chamber (Fig. 3). Which is where the material is disintegrated when the machine is running.

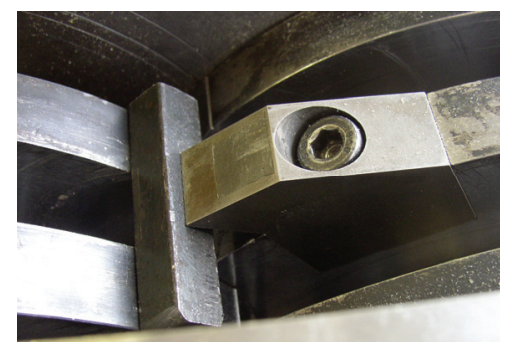

Fig. 3 Locking of wedge by steel block in sensor calibration process

The device is thus ready, the cables from sensors were connected to a measuring card, turn connected with a computer via Bluetooth interface. On the computer we start the communication program Syncom Data Acquisition. In the program we set the sampling frequency at $1000 \mathrm{~Hz}$, 
switch on the monitored channels, which are connected to the sensors and select the measurement range of the card (in our case, the channels 3 and 4 and the measuring range of card is $\pm 10 \mathrm{~V}$ ). Then we activated the graphic mode to monitor the measurement process online.

At this moment, the whole measuring apparatus for measuring was prepared. In the Sync program Data Acquisition we start data collection from sensors and the measurement is running. By the torque wrench we attempt to rotate the shaft against the wedge, which is similar to the standard disintegration process. We apply pressure to the torque wrench, until it clicks, denoting the obtained torque value. In this moment we release the force on the torque wrench. Repeating the load again, together we do 7 repetitions to be able to statistically evaluate the measured values.

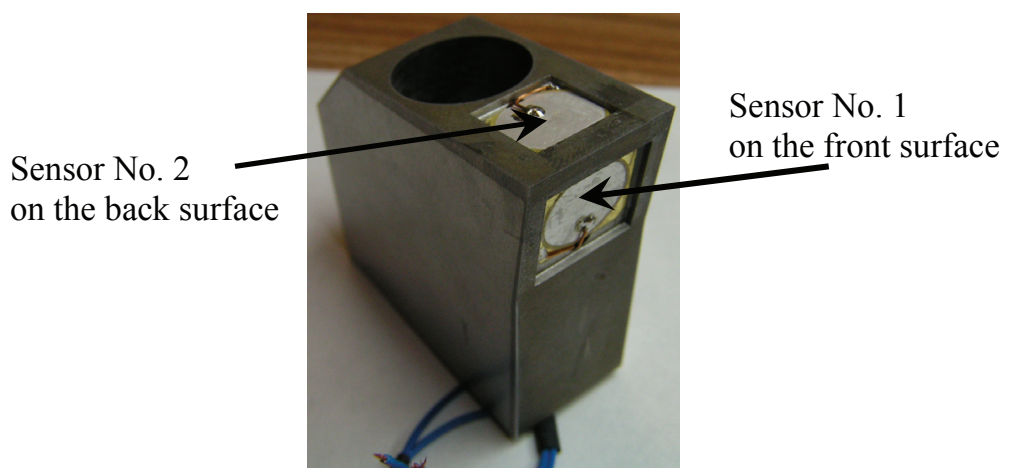

Fig. 4 Placement of the piezoceramic sensor on disintegrative wedge

Measured data is exported from Syncom Data Acquisition program to a text file, for example k1_2_100.txt. The file name indicates that it is sensor No. 2 on the wedge No. 1. Sensor No. 2 is located on the back surface of wedge. A value of 100 means that we measured at a torque of $100 \mathrm{Nm}$ set on the torque wrench. Then we import this file into MATLAB 6.5 where we can work with measured data. In Fig. 5 we can see the measured values processing graphically in the program MATLAB.

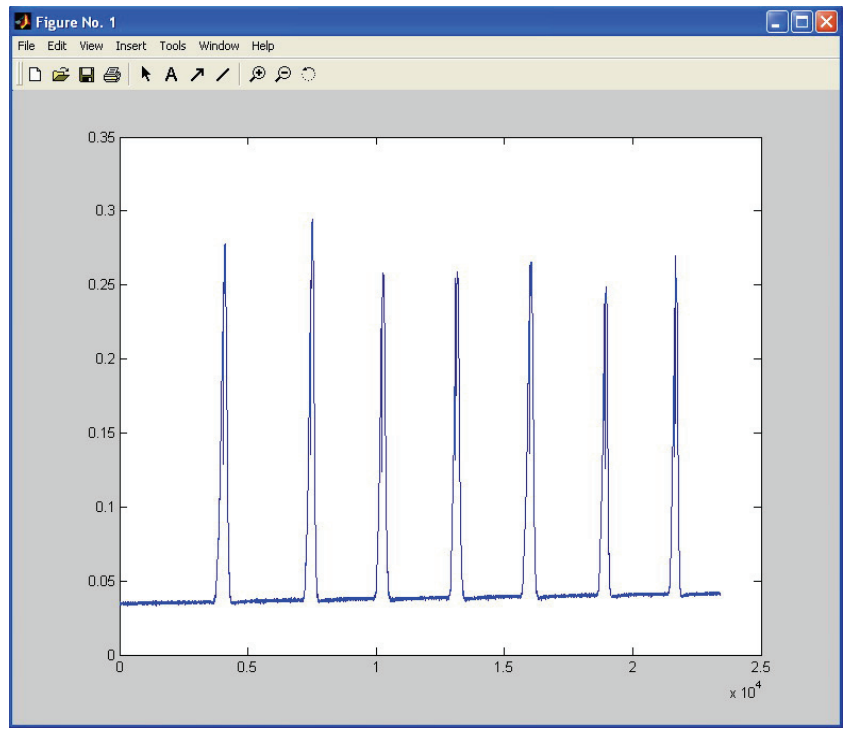


Fig. 5 Measured values of voltage in calibration of sensors

The seven peaks on the graph represent seven repeated measurements. In the following figure 6 is an enlarged part of the graph of one measurement from fig. 5. For each measurement we have to measure a lower voltage level before loading and the higher level when we reached the preset torque wrench value. The top level represents a sharp decline in the graph (the place where we reached the set torque value), then you can still see an upward trend of graph, what is effected by an additional force of the torque wrench, until it is released (torque wrench is not turned off completely, just gave a signal that we have reached the preset value, but we can still draw the torque wrench also after signal).

The difference between the lower level and higher level gives us the voltage that arose on the sensor by the deformation of the surface on which the sensor is placed, which has been deduced by a known torque value.

Already at the first calibration experiments we found that the measured values from sensor No. 1 on the face of the wedge will have no meaningful value. The reason for this statement is that the calibration and also direct measurement at the disintegration process, because the material is pushed directly to the sensor (surface of sensor through a layer of cement) and from measurement we obtained unusable values. Therefore, we decided not to use them in the measuring this sensor, or the values from him.

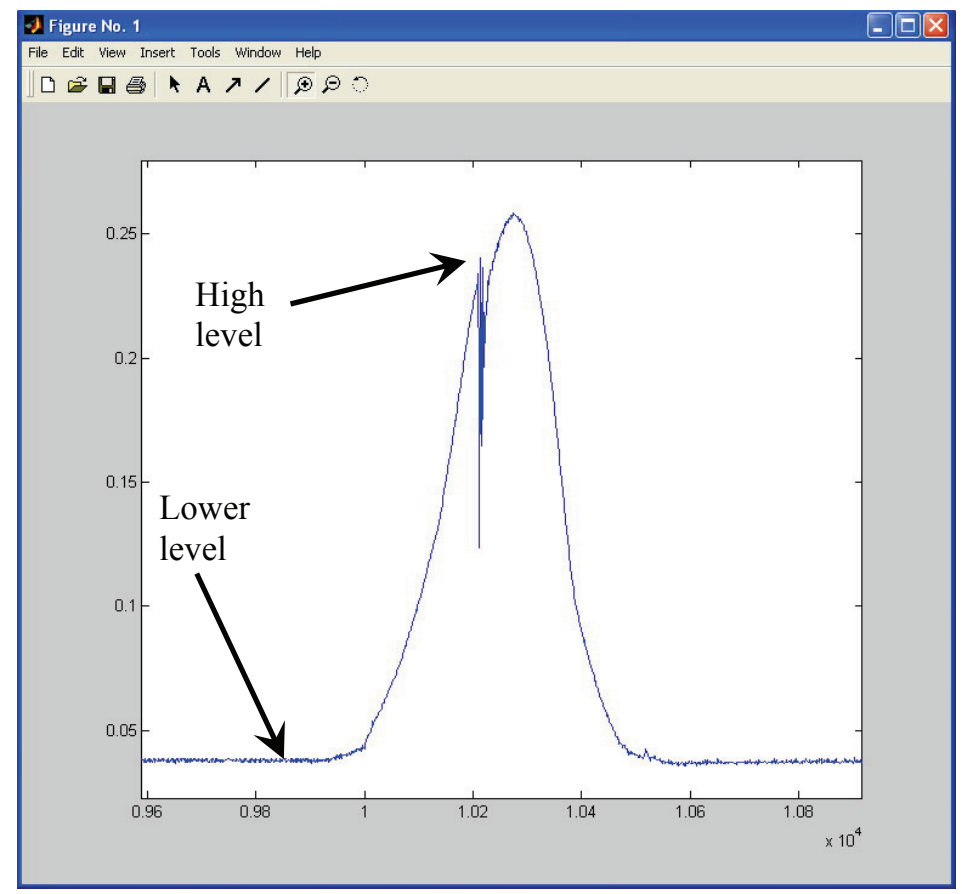

Fig. 6 Reading of values of voltage changes on sensors

\section{CALIBRATION OF DESITEGRATION WEDGES}

According to the procedure described above, we will realize the measurements with predetermined values of torque. Each measurement is repeated 8 times. 
Voltage values measured at different torque loads can be seen in Tables 1 to 3 . The summary table of the arithmetic average of individual measurements with standard deviation and uncertainty of measurements evaluated by the method type A we can see in the table No. 3 .

\begin{tabular}{|c|c|c|c|c|c|c|c|c|}
\hline No. & 1 & 2 & 3 & 4 & 5 & 6 & 7 & 8 \\
\hline$x_{i}=U \mathrm{e}(\mathrm{V})$ & 0.5098 & 0.5041 & 0.5060 & 0.5072 & 0.5065 & 0.5058 & 0.5075 & 0.5059 \\
\hline
\end{tabular}

Tab. 1 Measured values of voltage in calibration of wedge No. 1 for torque value $100 \mathrm{Nm}$

Arithmetical average: $\bar{x}_{100}=0,5066 \mathrm{~V}$

Standard deviation: $s(x)=1,72 \cdot 10^{-3} \mathrm{~V}$

Number of repetitions: $\quad n=8$

$$
\begin{aligned}
& \bar{x}=\frac{\sum_{i=1}^{n} x_{i}}{n} \\
& s(x)=\sqrt{\frac{1}{(n-1)} \sum_{i=1}^{n}\left(x_{i}-\bar{x}\right)^{2}}
\end{aligned}
$$

\begin{tabular}{|c|c|c|c|c|c|c|c|}
\hline No. & $\mathrm{x}_{\mathrm{i}(100)}=U \mathrm{e}(\mathrm{V})$ & $\mathrm{X}_{\mathrm{i}(150)}$ & $\mathrm{x}_{\mathrm{i}(200)}$ & $\mathrm{x}_{\mathrm{i}(250)}$ & $\mathrm{X}_{\mathrm{i}(300)}$ & $\mathrm{X}_{\mathrm{i}(350)}$ & $\mathrm{X}_{\mathrm{i}(400)}$ \\
\hline 1. & 0,5098 & 0,7836 & 1,0819 & 1,3722 & 1,7051 & 2,0235 & 2,3440 \\
\hline 2. & 0,5041 & 0,7739 & 1,0773 & 1,3692 & 1,6846 & 2,0139 & 2,3609 \\
\hline 3. & 0,5060 & 0,7814 & 1,0882 & 1,3994 & 1,6895 & 2,0023 & 2,3471 \\
\hline 4. & 0,5072 & 0,7831 & 1,0791 & 1,3751 & 1,6912 & 2,0211 & 2,3484 \\
\hline 5. & 0,5065 & 0,7788 & 1,0858 & 1,3881 & 1,6857 & 2,0097 & 2,3499 \\
\hline 6. & 0,5058 & 0,7791 & 1,0822 & 1,3797 & 1,6970 & 2,0226 & 2,3511 \\
\hline 7. & 0,5075 & 0,7809 & 1,0867 & 1,3814 & 1,6898 & 2,0102 & 2,3592 \\
\hline 8. & 0,5059 & 0,7760 & 1,0788 & 1,3773 & 1,7019 & 2,0023 & 2,3450 \\
\hline
\end{tabular}

Tab. 2 Measured values for the torque range of $100 \mathrm{Nm}$ to $400 \mathrm{Nm}$

\begin{tabular}{|c|c|c|c|}
\hline$y=M_{\mathrm{k}}(\mathrm{Nm})$ & $x=U_{\mathrm{e}}(\mathrm{V})$ & $s(x)$ & $u_{\mathrm{A}}(x)$ \\
\hline 100 & 0,0566 & $1,72 \cdot 10^{-3}$ & $0,63 \cdot 10^{-3}$ \\
\hline 150 & 0,7796 & $3,37 \cdot 10^{-3}$ & $1,27 \cdot 10^{-3}$ \\
\hline 200 & 1,0825 & $4,03 \cdot 10^{-3}$ & $1,52 \cdot 10^{-3}$ \\
\hline 250 & 1,3803 & $9,65 \cdot 10^{-3}$ & 0,003648 \\
\hline 300 & 1,6931 & $7,48 \cdot 10^{-3}$ & $2,83 \cdot 10^{-3}$ \\
\hline 350 & 2,0132 & $8,59 \cdot 10^{-3}$ & $3,25 \cdot 10^{-3}$ \\
\hline 400 & 2,3507 & $6,24 \cdot 10^{-3}$ & $2,36 \cdot 10^{-3}$ \\
\hline
\end{tabular}

Tab.3 Table of measured values in calibration process of wedge No.1

Dependence of the measured values of voltage from the torque is shown in Fig. 7 (solid line - blue color). In the same figure we have drawn through measured points a regression dependency type of polynomial of the third degree, which is shown by a dot - dashed line (red color). Transformation function is a polynomial of the third degree, which is normally used for the approximation. 
Transformational function for wedge No. 1:

$$
M_{\mathrm{k}}=0,9291 \cdot U_{\mathrm{e}}^{3}-12,931 \cdot U_{\mathrm{e}}^{2}+193,02 \cdot U_{\mathrm{e}}+5,8248
$$

where: $M_{\mathrm{k}}-$ torque $(\mathrm{Nm})$

$U_{e}$ - voltage $(\mathrm{V})$

We calibrated the rest of the disintegrative wedges by the same way.

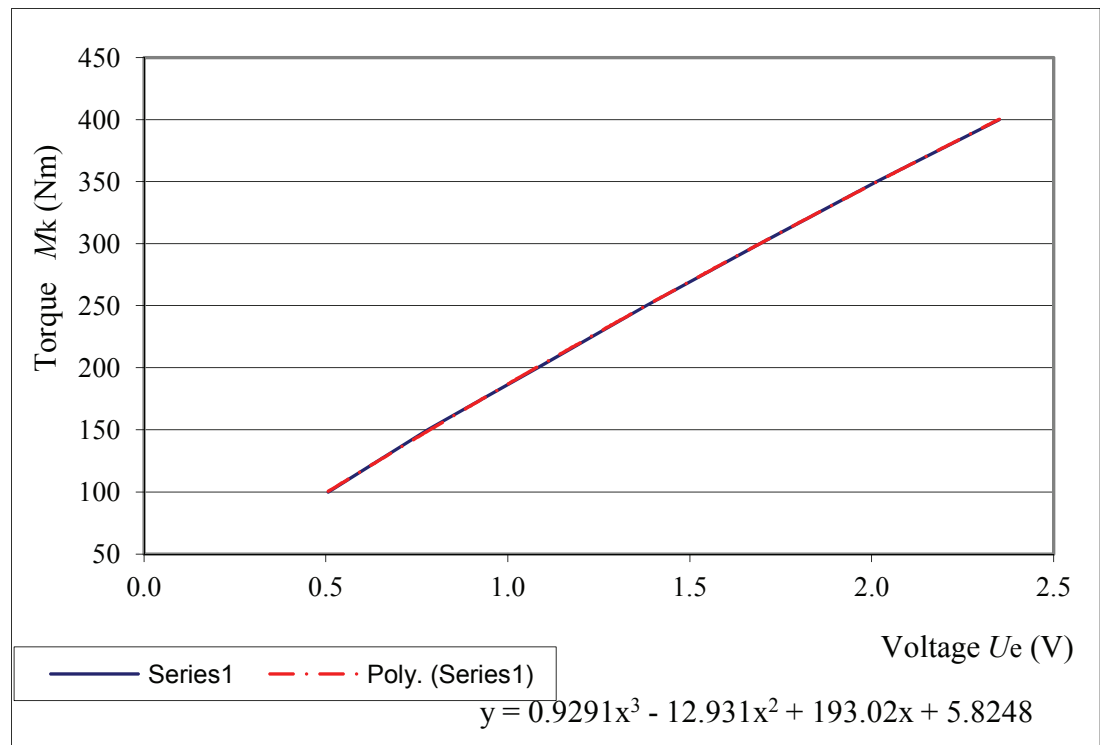

Fig. 7 Transformation curve of wedge No.1 with transformation polynomial

\section{CONCLUSION}

It is necessary to calibrate also the sensors which are placed on the other disintegrative wedges by the same way, and then we can come up with measurement values for the necessary torque in the process of real conditions of processing of material on disintegrative machine. Each sensor on each wedge must be calibrated separately, because each has a special wedge geometry, and each has a different size of sensor (sensing surface) adapted to the specific disintegration wedge. Also, even if there is a change on wedge geometry is necessary to recalibrate the sensors.

\section{REFERENCES}

[1] PALENČÁR, R., HALAJ, M.: Metrologické zabezpečenie systémov riadenia kvality, Vydavatel'stvo STU v Bratislave 1998, ISBN 80-227-1171-3

[2] PALENČÁR, R., RUIZ, J.M., JANIGA, I., HORNÍKOVÁ, A.: Štatistické metódy v metrologických a skúšobných laboratóriách, Grafické štúdio Ing. Peter Juriga, 2001, ISBN 80-968449-3-8

[3] HALAJ, M.: Kalibrácia piezorezistívneho maticového taktílneho snímača, Dizertačná práca, Bratislava 2001

[4] HALAJ, M.: Maticové taktilne snímače, Habilitačná práca, Bratislava 2006

[5] HB - náradie, s.r.o, Katalóg [online]. [citované dňa 15. mája 2007]. Dostupné z 
SCIENTIFIC PROCEEDINGS 2011, Faculty of Mechanical Engineering, STU in Bratislava Vol. 19, 2011, pp. 36-43, DOI: 10.2478/v10228-011-0007-y

<www.hbnaradie.sk $>$ 